\title{
Mind work of ideology: a function-operator perspective
}

\section{Pinich}

\author{
Kyiv National Linguistic University, Kyiv, Ukraine
}

Corresponding author. E-mail: ipinich@ @otmail.com

Paper received 13.12.17; Revised 19.12.17; Accepted for publication 22.12.17.

\begin{abstract}
https://doi.org/10.31174/SEND-Ph2018-151VI44-11
\end{abstract}
Abstract. The paper suggests an explanatory algorithm of ideology mind work by means of mathematical modeling of mental configurations processes. The correlation between the universal knowledge domain, conceptual and ideological pictures of the world are presented as operations of mathematical functions and their composition. The functions of ideological mentality and ideological doctrine are discerned on the basis of function properties.

Keywords: ideology, ideologeme, conceptual picture of the world, ideological picture of the world, function.

Introduction. A bipartite view on the role of ideology in shaping the modern world has ensued largely from current claims about its significance (or threat) as a social and political phenomenon. More recent interest to the allpervasive nature of ideology and the impact of ideological state apparatuses [19] in generating worldviews gives rise to a scientific trend of revisiting the notion of ideology, encompassing its reference to semiotics [11, 12], pragmatics [9], axiology, political and cognitive linguistics [6, 10], discourse analysis [5], and the theory of language. Yet, the plethora of standpoints as regards the issue in question is prone to multiply in number giving little evidence of ever establishing a clear-cut image of the matter. The hypothetic origin of the theoretical divergences resides primarily in the very definition of the phenomenon and the mechanisms of its functioning. This paper aims to give an overview of some already existing standpoints on ideological information processing summoned under a general idea of mathematical function.

Discussion. Earlier Hellenistic practices of studying ideational processes are the precedents of viewing dialectics as the reasoning dwelt on the commonplace, i.e. generally recognized knowledge. According to Aristotle, it follows that in a dialectic procedure to derive new knowledge the argument must ensure the truth of a conclusion drawn from apparently truthful premises [20, p. 181]. These self-evident truths or propositions per se serve the basis for argumentation, and may rest on endoxa, a system of 'shared beliefs' "accepted by everyone or by the majority or by the wise" [8]. Therefore, the shared beliefs might be interpreted as reputable, readily believable or plausible, based on the "views of any notable group or wise person worth attending to" [4, p. 209]. These plausible beliefs, subsequently, constitute the origin of the reputable standpoints stipulated by a dominant social group. The same holds of attendant values prescribed to a disputable matter. Yet, the dominant position may not necessarily coincide with the reputable beliefs, presumably causing the ambiguities between the commonly shared opinions and the endoxa. The dialectic model of reasoning between the social groups having claims on dominance may be far from the basis of reputable opinions, quite the contrary it may well contradict them. The only attainable goal of such reasoning procedures is to prove inconsistency of the opponents' counterfacts attributed to their incongruity with the shared beliefs through a rhetorical demonstration.

The commonplace which is also a set of beliefs shared by the opposing parties proves to be a pool of accepted knowledge of a more universal character as regards the dialectic modeling, for it may either include endoxa or lack it [4] and embraces a large number of enthymemes, i.e. "the syllogisms with suppressed premises" [17]. These common topics, which are most widely shared and apply across different fields of argument, are further reinterpreted in Boethius' maximal propositions [12] needed for providing belief to anything in doubt. Later, the medieval doctrine of the illation between the premises and conclusions was inherited by and served the basis for the medieval practices of argument. The arguments were regarded equivalent to conditionals and rested on maximal propositions [2, p. 246]. The grammar of propositional relationship mirrored the architecture of the arguments' domains established on the principles of opposition: contrariety, gradation, and genus. The successful rhetoric, therefore, exploited a well-trod path to public minds via the mechanisms of knowledge processing capable of guiding and directing the general pool of knowledge, serving therefore as "a strategy and a principle simultaneously" [20, p. 180].

Alongside, other conjectures on the nature of ideology modern claims often refer to it as a system of beliefs "held in common by the members of a collectivity..., a system of ideas which is oriented to the evaluative integration of the collectivity" $[13, \mathrm{p} .236)]$ and a "pertinent focus for the study of the structure and function of ideological mentality" [18, p. 399]. According to Parsons, relation of belief systems to societal existence and its further development lies in the interaction preeminently based on "a sharing and a relative stability of meaning" and yields to "cognitive symbol systems" [13, p.221] refracted in language. The common senses, subsequently, arise from a shared symbolic system as a result of the imposer of conventions and are governed by a normative order of cognitive, cathectic and moral standards. A cognitive primacy focus, as it follows further, sets the category of the existential beliefs into empirical and nonempirical which if viewed within evaluation category, establish the empirical reference to ideology and nonempirical to religious beliefs.

Semiotically oriented views on ideology undergird axiomatical systems over apodictic syllogisms with the reference no longer to "Absolute Reason" but to "emotional elements, historic evaluations and pragmatic motivations" [7, p.278]. Notwithstanding, the principle of ideological mechanisms are comparable to those of dialectic reasoning for disguised ideological premises derive ideological enthymemes subjected to extra-logical condi- 
tions with the further aim to produce the reasons for sensible human interaction. Yet, the shift from classical dialectics with the inventory of overt enthymemes and an aim of deriving plausible conclusion to a disguised ideological inventio of pragmatic and emotional influence on the audience marks a boundary between philosophy and politics. Therefore, Sartori concedes a distinction between an ideological doctrine (ideology of knowledge) and an ideological mentality (ideology of politics) in the study of ideology [18, p. 398]. Though deemed ontologically indispensible, the first is co-referenced to the extent of ideological conditioning of the mind and the latter seeks to observe the sociology of knowledge in an ideological culture. Bakhtin and Medvedev go further in assigning the role of an all-pervasive phenomenon to ideology built in many other aspects of human life such as science, religion or art [11]. Nonetheless, as Eco highlights, ideology serves a residue of meta-semiotic nature capable of directing semiosis yet irrelevant to culture coding [7, p.289].

In a nomiotic-wave theory, the inherent logic of nomiotic processes resides in co-elaboration of significant information at all mental levels and connects to the material logic of Boethius of correlating different information in view of its contents significance [3, p.41]. Bianca defines nomiosis as a procedure of generating inherent significance to all mental configurations and confines nomiotic procedures to a two-way process: that of significance generation and of processed information accumulation (ibid.). The nature of nomiotic processes is the same as their elaboration and is instantiated in a correlation between an idea and motivation through nomiotic bonds. The motivation of transcribing one's internal feelings, moods or ideas or other mental concepts into lingual signs results in propositional transpositions involving successive semiosis of mental configurations into lexemes. In addition, simultaneity of nomiosis and semiosis establishes a strong correlation between a prior intentionality, emotional inclusively [16], and the expression of mental concepts and emotions by means of language or other signs. Other proofs for the correlation between nomiotic and semiotic processes can be observed in the procedures of mental concepts production.

Cognitive studies among other significant aspects of elaboration on the nature of thought and language relation make a distinction between the conceptual picture of the world and a conceptual system of a language. The conceptual picture of the world represents "the full base of knowledge about the world (prescientific and scientific), saved up for all history of existence of the nation" [15] and is wider than the notion of the conceptual system. The knowledge within the conceptual picture of the world is irreducible to a language concept system which undergoes the processes of desemantization or archaization; on the contrary, it serves the pool for any kind of information learned or acquired throughout the history of a nation and is co-referent to Aristotelian commonplaces. The fact of the knowledge base by far exceeding the conceptual base of language denies their overlap, but rather justifies their congruence in the intentional translation of significant information to a set of concepts realized in linguistic signs.

A view on ideology being at the root of semiosis helps allocate it within the scope of nomiosis with its contem- poraneous processing of all the information subsequently resulting in the correlation of significant mental configurations. In logic and abstract algebra, the correlation between arbitrary sets is seen through a function or mapping of elements from one set to the other/others. Therefore, if mental configurations are viewed as mathematical arguments (elements), it would be germane to metaphorically arrange them in a set of non-numeric inputs defined within a set of a domain.

The domain encompasses input data of mental configurations retaining the features of compositional coelaboration of either explicit or covert types of awareness based on commonly recognized belief systems. The shared mental basis makes up the input mental configurations of the conceptual picture of the world arranged in a subset C. The elements (c1...cn) of the subset $\mathrm{C}$ entail information of different forms of awareness: social, political, religious, economic, moral and emotional, and further map to a subset I which stands for ideologically charged output images of mental configurations (i1... in). The images suggest a set of outputs within a codomain. Ideologemes as minimal fundamental units of ideologies are viewed as subsets within each $11 \ldots$ in $\subset$ I, serving cognitive-semiotic ties in the "dynamic nature of language meaning" production [22, p. 16]. The figure (Figure 1) shows the correlation of a domain of mental configurations and a codomain of "ideologically charged" $[14$, p. 3] outputs under a function of ideological doctrine.

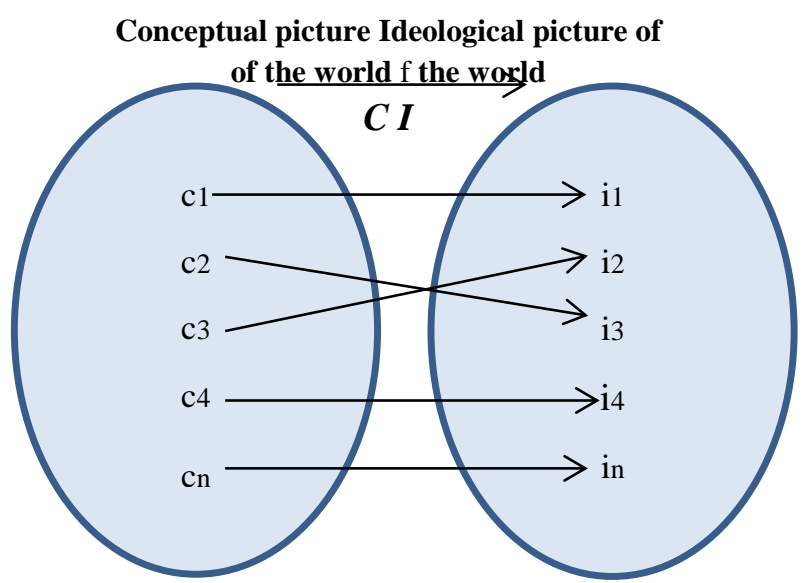

Figure 1. A function correlating input mental configurations of conceptual picture of the world and output ideologically charged configurations

The ideology as a function associates ideologically charged mental configurations with the mental configurations of a conceptual picture of the world viewed as coelaborated information of common knowledge. Any element of the codomain $\mathrm{i} \subset \mathrm{I}$ is the value of the ideological function at a corresponding $\mathrm{c} \subset \mathrm{C}$. The relation results in a typology of respective ideologies (political, social, economic, religious, moral, and emotional). The cardinality of the $\mathrm{C}$ domain yields the respective cardinality of I domain resulting in the equinumerosity of the domains $\mathrm{C} \approx \mathrm{I}$. The equipollence presumption translates to the axiom of choice with the input mental configurations of the conceptual picture of the world seeking the symmetry with the output set of ideologies cultivated within the multitude of social groups of a given society. 
The claim is substantiated by the compositional nomiosis of the information of "relevant selfic significance" [3, p.311] that restricts the cardinal number of input configurations and serves prerequisite to output mappings.

The function of ideological doctrine is presumably bijective by nature, employing both "one-to-one relation (injection) and one-to-one correspondence (surjection)" $[1$, p. 15]. The injective relation entails a one-to-one reference of every c element to i element. Put it in a formulaic fashion, if $\mathrm{c} 1 \neq \mathrm{c} 2$, then $\mathrm{f}(\mathrm{c} 1) \neq \mathrm{f}(\mathrm{c} 2)$ and equivalently, if $\mathrm{f}(\mathrm{c} 1)=\mathrm{f}(\mathrm{c} 2)$, then $\mathrm{c} 1=\mathrm{c} 2$. The injective function denies the possibility for the same value $\mathrm{i}$ at different $\mathrm{c}$, so $\mathrm{f}(\mathrm{c} 1) \neq \mathrm{f}(\mathrm{c} 2) \neq \mathrm{i} 1$. The surjection implies that for any $\mathrm{i}$ in I there is at least one $c$ in $C$ such that $f(c)=i$. The formula testifies to a one-to-one correspondence between ideological configurations and mental configurations of conceptual picture of the world.

Given that conceptual mental configurations are functions by themselves and constitute input truth values standing in relations of opposition: contradiction, contrariety, sub-contrariety and sub-alternation [21]; a composition of functions is observed. The composite function is the ideological mentality function operating as ideological conditioning of the mind. Figure 2 is aimed at visualization of function composition.

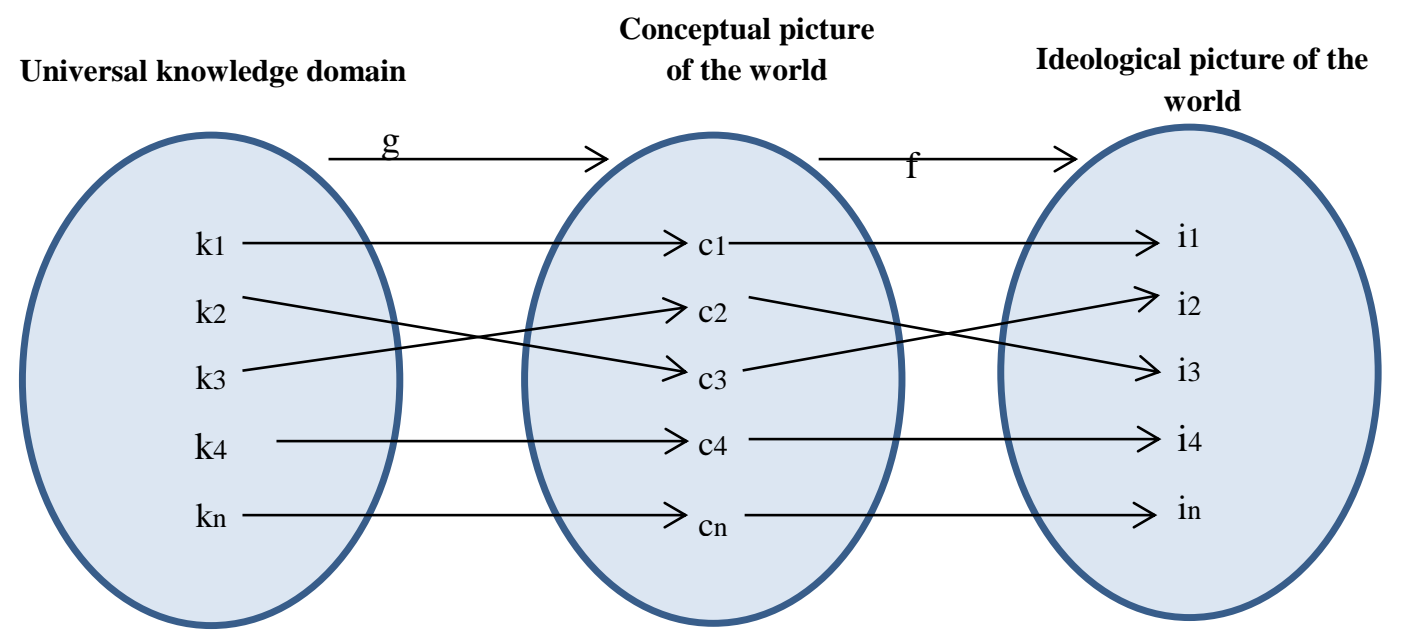

Figure 2. Function composition in transforming universal knowledge to ideologically charged configuration

Significant mental configurations in the universal knowledge domain with every $\mathrm{k} \subset \mathrm{K}$ are transformed to a conceptual knowledge range of concepts in the codomain $\mathrm{C}$ under the function of conceptual co-elaboration $\mathrm{g}(\mathrm{k})$. Consequently, the pointwise application of $\mathrm{g}$ yields the relation established between the domain and the codomain as an intermediary of a chaining process. Further, following the chain algorithm the function of ideological doctrine maps $\mathrm{c} 1 \ldots \mathrm{cn}$ to ideological configurations in I. Correspondingly, a composite function $\mathrm{f}(\mathrm{g}(\mathrm{k})$ ) maps $\mathrm{k} 1 \ldots \mathrm{kn}$ to $\mathrm{i} 1 \ldots$ in and functions as an operator. The composition of functions results in the composition of relations associative in their nature. Intuitively, the composition of one-to-one correspondence outputs in a one-to-one function. Similarly, the composition of two onto functions makes a one-to-one relationship. It follows that the composition of two bijective functions is also a bijection.

To observe the relation between the systems of mental configurations and language, linguistic picture of the world (L) may too be viewed as a combination of functions. Ideology and language are both systems of the unconscious that articulate senses into semic systems. Although, ideology as a principle of sense generation doesn't make up an inventory of contents nor it is a set of semantic rules for generating messages [13, p.15]. The claim about the ideological mentality as a composite function-operator suggests the very mechanisms of sense production, a way of thinking, involved in all the procedures of mental co-elaboration processes. Meanwhile, the ideological doctrine functions transpose mental configurations to legitimize the ideas of the beneficiary and are employed in a combination of functions for language production: $\mathrm{f}(\mathrm{c})+\mathrm{g}(\mathrm{k})+\mathrm{f}(\mathrm{g}(\mathrm{k}))$. The configurations may vary from a sum and difference to a product and quotient. Alongside, language production function is a multi-variable function $1(\mathrm{k}, \mathrm{c}, \mathrm{i})$, the choice of operands under which is substantiated by individuals' motivation.

Conclusions. A combination of viewpoints based on traditional logic and a nomiotic theory of inherent logic gave rise to the idea of a chain model of mental transpositions presented as mathematical functions. The algorithm of ideology mind work is seen as co-elaboration of significant mental configurations in a universal knowledge domain through a range of concepts in a conceptual picture of the world and a set of ideologies in an ideological picture of the world. The linearity of the process was chosen to visualize the relation among the systems of knowledge by contingent single variable functions. Though, the notion of co-elaboration suggests not only several domains involved but also multiple inputs and multiple outputs, that translates to a multivariable calculus.

\section{REFERENCES}

1. Ash R.B. A Primer of Abstract Algebra. The Mathematical 2. Bellucci F. Charles S. Peirce and the Medieval Doctrine of Association of America, 1998. - 181p.

consequentiae // History and Philosophy of Logic, 2016, Vol. 37, Iss. 3. - P. 244-268. DOI:1080/01445340.2015.1118338 
3. Bianca M.L. The Nomiotic-Wave Theory of Mind and Inherent Logic. Newcastle upon Tyne: Cambridge Scholars Publishing, 2017. -495 p.

4. Bonevac D. Notes on Aristotle's Topics, Book III. [E. resource]. - Access mode: http://bonevac.info/348/Topics3.pdf

5. Van Dijk, T.A. Ideology and discourse analysis // Journal of political ideologies, 2006, Is. 11. - P. 115-140.

6 Dirven R., Polzenhagen F., Wolf H.-G. Cognitive Linguistics, Ideology, and Critical Discourse Analysis // The Oxford Handbook of Cognitive Linguistics, Oxford: Oxford University Press, 2007. - P. 1222-1240. DOI: 10.1093/oxfordhb/9780199738632.013.0047

7. Eco U. A Theory of Semiotics. Bloomington: Indiana University Press, $1976-354$ p.

8. Endoxa // The Blackwell Dictionary of Western Philosophy / Nicholas Bunnin, Jiyuan Yuohn, (eds.). Malden, MA, Oxford, Carlton, Victoria: Blackwell Publishing, 2004. - 776 p.

9. Gutiérrez-Rexach J., Schatz S. Social Cognition and the Pragmatics of Ideology // Pragmemes and Theories of Language Use. Perspectives in Pragmatics, Philosophy \& Psychology, 2016, Vol 9. - P. 625-642. DOI. 10.1007/978-3319-43491-9_32

10. Jost J., Federico Ch. M., Napier J. L. Political Ideology: Its Structure, Functions, and Elective Affinities // Annual Review of Psychology, 2009, Vol. 60: - P. 307-337

11. Marling W. The formal ideologeme // Semiotica, 1994, Is. (3-4). - P. 277-300. DOI.10.1515/semi.1994.98.3-4.277

12. Nöth W. Semiotics of ideology. [E. resource]. - Access mode: http://www.zbi.ee/ kalevi/148_11.pdf?q=semiotics

13. Parsons T. The Social System. London: Routledge, 1991. $448 \mathrm{p}$.
14. Percy C., Davidson M. C. The Languages of Nation. Bristol, Buffalo, Toronto: Multilingual Matters, 2012. - 306 p.

15. Pimenova M. Conceptual Investigations. In Modern Linguistics. Linguistic Studies, 2013, Vol 27. - P. 23-29.

16. Pinich I.P. Pragmatics of emotionality in discourse processing: prolegomena to ideology shaping engines. //Lege artis. Language yesterday, today, tomorrow. The Journal of University of SS Cyril and Methodius in Trnava. Warsaw: De Gruyter Open, 2017, Vol. II(1). - P. 262-298. DOI: 10.1515/lart-2017-0007

17. Rapp Ch. Aristotle's Rhetoric // The Stanford Encyclopedia of Philosophy (Spring 2010 Edition),

Zalta E. N. (ed.), [E resource]. - Access mode: https://plato.stanford.edu/archives/spr2010/entries/aristotlerhetoric/

18. Sartori G. Politics, Ideology, and Belief Systems. // The American Political Science Review. - Vol. 63, No. 2 (Jun., 1969). - P. 398-411. DOI: 10.2307/1954696

19. Sevgi H., Ozgokceler S. Media and Cerattepe in Turkey: Althusser's communications ideological state apparatus [ISA] - oriented assessment // In Eurasian Journal of Social Sciences, 2016, 4(3). - P. 14-24. DOI: 10.15604/ejss.2016.04.03.002

20. Stump E. Boethius's De Topicis Differentiis. Ithaka and London: Cornell University Press, 2004. - 287 p.

21. The Traditional Square of Opposition // The Stanford Encyclopedia of Philosophy (Spring 2010 Edition), Zalta E. N. (ed.), [E. resource]. - Access mode: https://plato.stanford.edu/entries/square/

22. Zlatev J. Cognitive Semiotics: An emerging field for the transdisciplinary study of meaning // The Public Journal of Semiotics, 2012, IV (1). - P.2-24.

\section{Работа мысли идеологии: функционально-операторный подход}

\section{И.П. Пинич}

Аннотация Статья предлагает алгоритм объяснения идеологической работы мысли с помощью математического моделирования процессов обработки ментальных конфигураций. Соответствия между областью универсальных знаний, концептуальной и идеологической картинами мира представлены в виде операций математических функций и их композиции. Разграничиваются функции идеологической ментальности и идеологической доктрины на основе базовых характеристик функций.

Ключевые слова: идеология, идеологема, концептуальная картина мира, идеологическая картина мира, функичя. 